Reprod. Nutr. Dévelop., 1986, 26 (1 B), 387-388.

\title{
Evolution des lipides plasmatiques et d'hormones sanguines en cours de croissance-engraissement chez l'agneau
}

\author{
T. HEINS, Fr. VERNAILLEN, R. PAQUAY
}

Facultés Universitaires, Physiologie animale, B-5000 Namur, Belgique.

Summary. An experiment was carried out on ten Texel lambs from birth to six months in order to study plasma lipid and hormonal changes. Plasma lipid composition and hormonal levels varied greatly from birth to weaning as a result of the change in diet. Wide differences were also seen after weaning, especially between males and females.

Les processus physiologiques et métaboliques mis en jeu au cours de la période de croissance-engraissement ont été appréciés par la comparaison, chez des agneaux et des agnelles, des paramètres du développement corporel (poids vif, gains en poids, composition corporelle) et des concentrations sanguines de substances lipidiques et hormonales.

Matériels et méthodes. Dix agneaux Texel, 5 mâles et 5 femelles, nés entre le 6 et le 22 novembre restent avec leur mère jusqu'au sevrage qui a lieu à un âge moyen de 67 jours. Dès la $3^{e}$ semaine, ils ont libre accès à un aliment composé granulé qu'ils reçoivent jusqu'à la fin de l'expérience.

Après le sevrage et jusqu'à l'âge de 6 mois, ils sont placés en boxes individuels et reçoivent à volonté du foin de prairie et l'aliment composé. La vitesse de croissance moyenne entre la naissance et la fin de l'expérience (185 jours) est de $226,5 \pm 22 \mathrm{~g} / \mathrm{j}$.

A partir du 12 décembre, des prises de sang sont effectuées tous les 14 jours à $10 \mathrm{~h}$ par ponction veineuse. Les substances lipidiques sanguines sont déterminées par densitométrie et chromatographie en phase gazeuse. L'insuline, l'hormone de croissance $(\mathrm{GH})$ et les hormones thyroïdiennes (T3, T4) plasmatiques sont mesurées par radioimmunologie.

Résultats (fig. 1) et discussion. En cours d'allaitement, les principales modifications sont une augmentation de la proportion des phospholipides dans les lipides sanguins, une diminution de celle des esters de cholestérol de même que des proportions d'acide palmitique dans les triglycérides et $d$ 'acide myristique dans les esters de cholestérol. On peut noter une chute assez brusque dans la teneur en acides gras libres juste après le sevrage. Ces modifications peuvent être mises en relation avec la diminution progressive de l'alimentation lactée au profit de l'aliment composé. La période d'allaitement est aussi marquée par une diminution des concentrations en $\mathrm{GH}$ et T3 du sang, évolution bien connue au début de la vie (Johns and Bergen, 1976).

En cours de croissance-engraissement, il se produit une augmentation de la proportion des esters de cholestérol chez les mâles et des pourcentages de $C_{16: 0}$ dans les phospholipides et de $\mathrm{C}_{18: 2}$ dans les triglycérides et les esters de cholesté- 
rol. En fin de période, les valeurs sont assez comparables à celles de Nelson (1969).
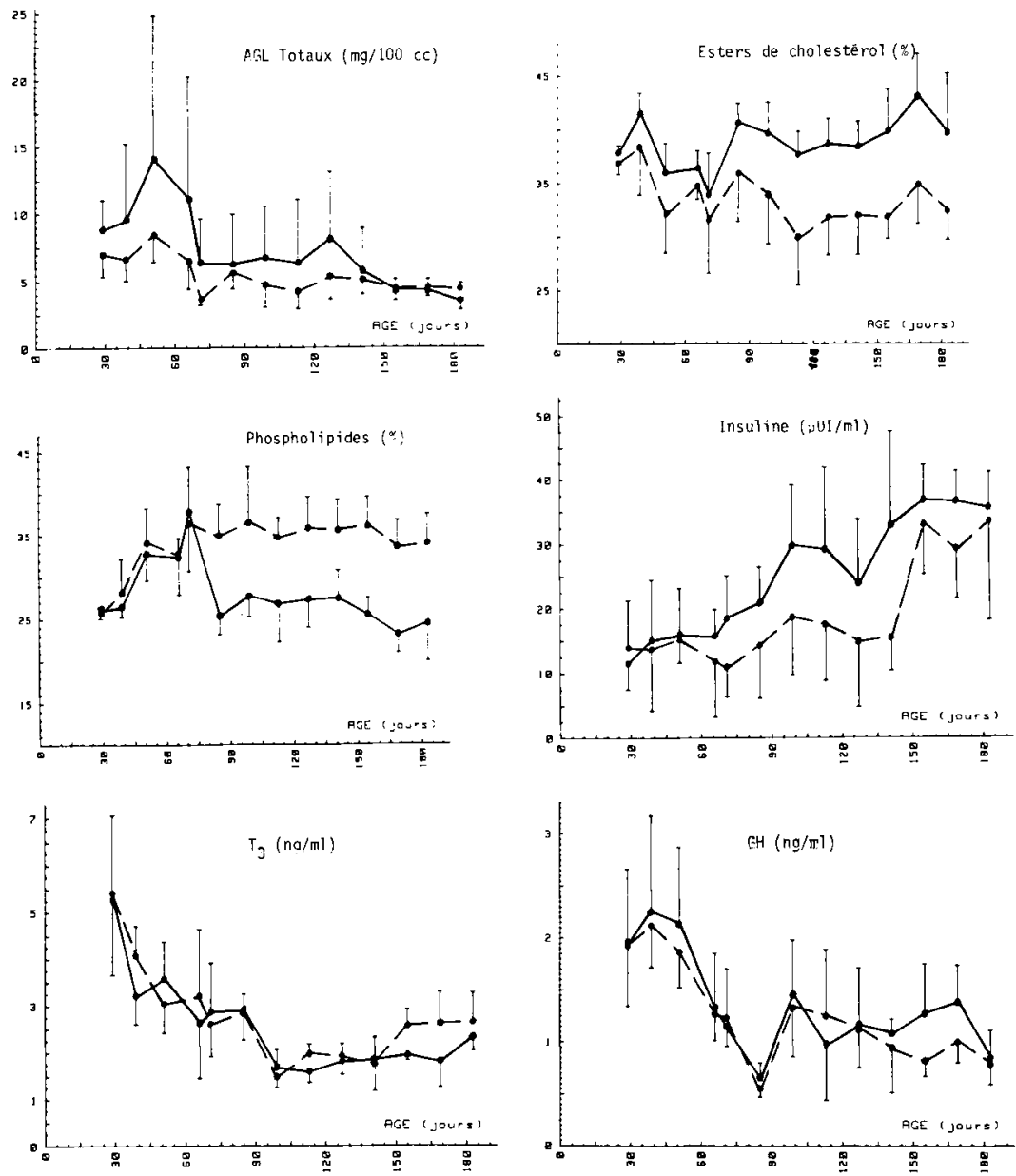

FIG. 1. - Evolution des teneurs en acides gras, des lipides et des hormones plasmatiques en cours de croissance-engraissement chez l'agneau Texel.

Les mâles présentent généralement une proportion significativement moindre $\{\alpha=0,01\}$ de phospholipides qui est compensée par une proportion plus grande d'esters de cholestérol $(\alpha=0,01)$ et de triglycérides.

Les concentrations de T3 et de GH diminuent après le sevrage. Au contraire, celle d'insuline augmente, et cela de manière significativement plus importante chez les mâles que chez les femelles $(x=0,05)$.

Johns J. T., Bergen W. G., 1976. Growth in sheep. Pre- and post-weaning hormone changes and muscle and liver development. J. anim. Sci, 43, 192-199.

Nelson G. J., 1969. The lipid composition of whole plasma of hampshire-sheep, ovis aries. Comp. Biochem. Physiol., 30, 715-725. 